Economía, Sociedad y Territorio, vol. vI, núm. 24, 2007, 975-994

\title{
Paradojas de la migración internacional y el medio ambiente
}

\author{
ROdOlFo García-ZaMora \\ Óscar PÉrez-Veyna \\ GUILleRMo Foladori \\ Raúl Delgado-Wise \\ Miguel Moctezuma-Longoria \\ ELIVIER REYES-RIVAS \\ Humberto Márquez-Covarrubias \\ Patricia Rivera-Castañeda*
}

\section{Resumen}

En el presente artículo se analiza la relación entre migración internacional y degradación ambiental, se estudia el caso de Zacatecas. Se identifican tres paradojas: a) factores como la degradación ecológica, la escasez de recursos naturales o la presión del crecimiento poblacional no explican la migración internacional; contrariamente, las causas se encuentran en la insostenibilidad social derivada de las relaciones de producción; b) merced a la migración, la fuerza de trabajo pasa de ser un recurso natural renovable a uno no renovable, en particular para la dinámica socioeconómica de los lugares de origen, y c) la migración puede gestar el empoderamiento de las organizaciones de migrantes en tareas vinculadas a la reversión de la degradación ambiental.

Palabras clave: Zacatecas, migración internacional, sostenibilidad, ambiente, despoblamiento, empoderamiento.

\begin{abstract}
In this article we analyse the relationship between international migration and environmental degradation. We analyse the case of Zacatecas. We identify three paradoxes: a) some factors such as ecological degradation, scarcity of natural resources or the pressure due to population growth do not explain international migration; on the contrary the causes can be found in the social unsustainability due to production relationships; b) due to migration, the work force is transformed from being a renewable natural resource to a nonrenewable one, particularly for the socio-economical dynamics of the place of origin, and c) migration can develop the empowerment of organisations of migrants in tasks related to the reversal of environmental degradation.
\end{abstract}

Keywords: Zacatecas, international migration, sustainability, environment, depopulation, empowerment.

* Todos los autores están adscritos a la Universidad Autónoma de Zacatecas, México. Correo-e de contacto: aire_tierra11@yahoo.com.mx. 


\section{Introducción $^{1}$}

La migración internacional es un fenómeno mundial en crecimiento: en 1970 se calcularon 82 millones de migrantes; en 2000, 175 millones, y en 2005, 200 millones (Banco Mundial, 2005). La principal causa es de índole económica, debido a la agudización de las desigualdades y asimetrías entre los países del norte (desarrollados) y los del sur (subdesarrollados), por lo cual más allá de la diversidad de las migraciones internacionales (refugio, asilo, reunificación familiar, etc.), el componente más importante de la migración contemporánea es de carácter laboral. ${ }^{2}$ No obstante, se pueden enumerar otras causas asociadas, como la violencia derivada de conflictos armados, la presión demográfica, las catástrofes naturales o la degradación ambiental en los lugares de origen.

México es el primer exportador de migrantes del mundo y el tercer receptor de remesas, en tanto que sus migrantes conforman el principal contingente extranjero en Estados Unidos, que a su vez es el primer país receptor de inmigrantes del mundo. Dentro de México, Zacatecas se ubica en el primer lugar en cuanto al porcentaje de hogares con migrantes, de remesas recibidas por hogar y de remesas como proporción del Producto Interno Bruto (PIB) estatal.

En lo que toca a la relación entre migración y ambiente, algunos autores han señalado las catástrofes naturales, la escasez de recursos naturales y la degradación ambiental como causas directas de las migraciones. Inclusive se ha relacionado la degradación ambiental y la escasez de recursos naturales, junto al incremento poblacional, como causantes de migraciones que afectan la seguridad nacional e internacional.

En este artículo analizamos la relación entre la migración de Zacatecas a Estados Unidos y la degradación ambiental en dicho estado con tres paradojas sintomáticas que contradicen la literatura sobre el tema y, también, al sentido común. La primera sostiene que no actúan como causa de migración la degradación

${ }^{1}$ Una versión preliminar de este trabajo se presentó en el congreso Ecology in an Era of Globalization, organizado por la Ecological Society of America, en Yucatán, México, del 8 al 12 de enero de 2006.

${ }^{2}$ La Organización Internacional del Trabajo (orT, 2006) estima que en el mundo hay 90 millones de trabajadores migrantes, que equivalen a 3\% de la fuerza laboral global. Ese flujo se asocia con el desempeño de las cadenas globales de producción y con los procesos de flexibilización y precarización laboral en los que participan tanto los países receptores como los emisores (Delgado Wise y Márquez, 2006). 
ecológica o la escasez de recursos naturales, o bien la presión que ejerce el crecimiento poblacional, sino que la causa es insostenibilidad social. La segunda argumenta que la migración está convirtiendo a un recurso natural renovable, la fuerza de trabajo, en uno no renovable para las comunidades de origen. La tercera dice que la migración se puede constituir en un proceso de empoderamiento para revertir la degradación ambiental, contradiciendo de esta forma lo aseverado en la segunda paradoja, pero mostrando la dialéctica que la relación entre migración y ambiente tiene en el caso de Zacatecas.

\section{Primera paradoja: no es la degradación ambiental, sino la insostenibilidad social, la que actúa como causa de la migración Zacatecas-Estados Unidos}

La relación entre migración y ambiente ha dado lugar a una extensa bibliografía. Algunos autores sostienen que los problemas ambientales se pueden convertir en causa de migración. Norman Myres (2005) señala que el calentamiento global de origen antrópico podría provocar un aumento del nivel del mar con la consecuente expulsión de 200 millones de personas de las zonas costeras para 2050. Cuando la Organización de las Naciones Unidas (ONU, 1991) identifica "zonas ecológicas críticas", es claro que está privilegiando problemas ambientales como causa de migración. El término refugiados ambientales, utilizado ampliamente por autores e instituciones, transmite la idea de que la causa de la migración radica en algún tipo de crisis ambiental (Myres, 2005; Suhrke, 1994; El-Hinnawi, 1985). Jodi Jacobson (1988) sostiene que la degradación del suelo, provocada por un mal manejo, deriva en migraciones masivas en el área del Sahara. Michelle Schwarts y Jessica Notini (1995) argumentan de forma similar, y hacen extensivo el ejemplo a México, Haití, el nordeste brasileño y el noroeste indio. Ashok Swain (1996) se refiere al mayor estrés ambiental en los países en desarrollo por prácticas degradantes. Cuando Thomas Homer-Dixon (1994) señala la escasez de recursos naturales renovables como causa de violencia ambiental y migración, también privilegia la insostenibilidad ecológica en el análisis (aunque reconozca que son las propias actividades humanas las que degradan los recursos, o que se genera escasez por la presión del incremento poblacional o la desigual distribución de recursos).

En otros casos son los desastres naturales provocados por eventos climáticos extremos (catástrofes) los que aparecen como 
causa; y los medios de comunicación establecen relaciones mecánicas entre los ciclos de sequía y la migración en el Sahara, o los ciclos de sequía y las inundaciones en India o Bangladesh, y en otros países o regiones. ${ }^{3}$

Otros critican el argumento de que los problemas ambientales se convierten automáticamente en causa de migración. ${ }^{4}$ En todo caso, los problemas ambientales podrían ser causas inmediatas, pero existen situaciones más profundas o estructurales relacionadas con la pobreza o los estilos de desarrollo (Hugo, 1996; Richmond, 1995; Suhrke, 1994).

Es claro que la discusión gira en torno a privilegiar la insostenibilidad ecológica o la insostenibilidad social como causa de la migración. Cuando se habla de desarrollo sostenible se considera que existen tres grandes áreas que agrupan los diversos elementos que encierra el concepto. Estas áreas son: la sostenibilidad económica, cuya viabilidad supone eficiencia, rendimiento y competitividad; la sostenibilidad ecológica, que supone garantizar la salud ecosistémica, la biodiversidad de especies y la riqueza genética; y, finalmente, la sostenibilidad social, que se refiere a la equidad y condiciones de vida en general. De allí que cuando se relacione la migración con la problemática ambiental, algunos autores digan que el deterioro de los ecosistemas (o sea, la sostenibilidad ecológica) puede ser la causa principal de las migraciones, mientras que otros argumentan que la causa principal son las condiciones sociales y económicas de pobreza e inequidad (o sea, la sostenibilidad social). El problema es que mientras la relación causal entre erosión del suelo y migración, o entre sequías o inundaciones y migración, resulta fácil de visualizar -y atractiva para los medios de comunicación-, no es tan fácil entender cómo la pobreza o los estilos de desarrollo, que son conceptos más generales y abstractos, pueden relacionarse directamente con la migración.

El análisis del caso zacatecano nos enseña que los factores ambientales se traducen en relaciones sociales para convertirse en causantes de migración. La erosión derivada de un mal manejo del suelo, por ejemplo, no puede expresarse directamente como causa de migración, porque no actúa por sí misma, sino que lo hace una vez valorada en los precios relativos del suelo y sus

${ }^{3}$ Aunque la relación causal entre sucesos naturales extremos y migración resulta atractiva, cuando se asume como explicación política justifica que se privilegie el desarrollo de la ciencia y la tecnología para “corregir” el ambiente sobre la disminución de la vulnerabilidad humana asentada en las áreas críticas (Foladori, 2005).

${ }^{4}$ Richard Black (2001) hace una crítica a todas las posiciones que adjudican causas ambientales a las migraciones. 
productos, y en los cuales se entrelazan otros muchos factores sociales, económicos y culturales que convierten la fertilidad físico-natural en fertilidad económica.

La migración laboral de México a Estados Unidos lleva más de un siglo, pero en la última década ha experimentado un aumento sin precedentes. El saldo neto migratorio internacional promedio anual aumentó 20.5 veces en el curso de las últimas cuatro décadas y media, cuando pasó de 28 mil migrantes en los sesenta a 575 mil en el lustro comprendido entre 2000 y 2005 (Conapo, 2004, 2006). Zacatecas se ubica en la llamada zona histórica de la migración mexicana; cuenta con 74,669 km² de suelos, en su mayoría semidesérticos, y con 1'384,512 habitantes (Conapo, 2006). Dentro del país, Zacatecas se erige como la principal entidad de migrantes, por el porcentaje de su población que reside en Estados Unidos, la intensidad con la que se manifiesta el fenómeno en los hogares, la participación femenina y el monto e importancia económica de las remesas (Delgado Wise, Márquez y Rodríguez, 2004).

Zacatecas es el primer productor de frijol en México, con cerca de 31\% de la producción nacional; de ésta, 76\% es de temporal (Sagarpa, 2004). Entre 1987 y 2003, el frijol representó cerca de $57 \%$ del total de la superficie sembrada y cosechada del estado, y $31 \%$ del total del valor generado por la agricultura (Sagarpa-Sedagro, 1987-2003). Es claro que se trata del principal producto agrícola del estado, y que, debido al carácter temporalero de su producción, las prácticas agrícolas resultan altamente determinantes de la sostenibilidad de sus suelos.

Según investigadores del Instituto Nacional de Investigaciones Forestales, Agrícolas y Pecuarias (INIFAP), en Zacatecas más de 150 mil hectáreas de tierras de cultivo están en proceso de desertificación y otras 300 mil sufren erosión severa. Debido al tipo de práctica agrícola imperante, anualmente se pierden de 35 a 40 toneladas de suelo por hectárea, situación que afecta gravemente a municipios como Sombrerete y Juan Aldama, que se cuentan entre los principales productores de frijol (Valadez, 2005).

No obstante la degradación del suelo, en los últimos 16 años no hubo reducción de la superficie cultivada ni de sus rendimientos, más allá de las variaciones cíclicas adjudicables al carácter temporalero de la producción. ${ }^{5}$ Pero esto no significa que no haya migra-

${ }^{5}$ Degradación de los suelos, por un lado, y mantenimiento de rendimientos y producción, por otro, resultan aparentemente en una paradoja. Sin embargo, una cosa 
ción. Al contrario, entre los principales municipios con migrantes se encuentran los de mayor rendimiento y producción de frijol. Sombrerete y Juan Aldama, por ejemplo, ubicados como los principales productores de frijol del estado, tienen índices de intensidad migratoria alto y muy alto, respectivamente (Conapo, 2002). Por esta razón está habiendo un notorio proceso de envejecimiento de los productores, cuyos hijos migran a Estados Unidos.

El ejemplo de Zacatecas es apropiado para una argumentación mecánica del siguiente tipo: prácticas agrícolas insostenibles provocan desertificación que a su vez genera migración. Pero ésta sería una conclusión errada. Las malas prácticas agrícolas causan degradación del suelo, pero es necesario que el producto del suelo erosionado compita desventajosamente en el mercado para convertirse en causante de migración.

Esto último ha venido sucediendo en Zacatecas desde mucho tiempo atrás. Por un lado, los rendimientos físicos colocan a la entidad en situación desventajosa frente a otros estados mexicanos. Para la producción temporalera del ciclo primavera-verano, el de mayor producción de la entidad, los rendimientos se ubican por debajo del promedio nacional. Por ejemplo, en 2003 Morelos registró una producción de 1,250 kg/ha; Colima, 980; Estado de México, 960, y Zacatecas, 442; en tanto que la media nacional fue de $610 \mathrm{~kg} / \mathrm{ha}$ (Sagarpa, 2004). Por otro lado, los precios del producto han disminuido, no así los costos de producción, lo cual establece una brecha en detrimento de los productores. La gráfica 1 ilustra la tendencia descendente de los precios en comparación con la producción total de frijol en México.

Las dos visiones de la relación entre deterioro ambiental y migración podrían exponerse de forma esquemática como sigue: ${ }^{6}$

- Las malas prácticas agrícolas provocan degradación del suelo y, consecuentemente, son causantes de migración. ${ }^{7}$

es la degradación del suelo en términos absolutos, como lo mide la erosión, y otra muy diferente la posibilidad de utilizar ese suelo para producir un determinado cultivo. En el caso del frijol, la erosión puede manifestarse en rendimientos diferenciales después de un tiempo más prolongado; además hay otros factores que inciden -como es el caso de los insumos, que se combinan con la fertilidad natural para un mayor rendimiento-, en el hecho de que cosechas exiguas, como las que hay en Zacatecas, hagan que las variaciones por fertilidad tengan impactos menores.

${ }^{6}$ Es claro que muchos otros factores inciden en la relación ambiente-migración en ambas visiones, pero aquí abstraemos los elementos centrales para facilitar su comparación.

7 "Los hallazgos contenidos en este informe sugieren que un serio debilitamiento de las tierras agrícolas de México puede ocasionar migración. Hay evidencia que sugiere 


\section{Gráfica I}

\section{Volumen y valor de la producción de frijol en México}

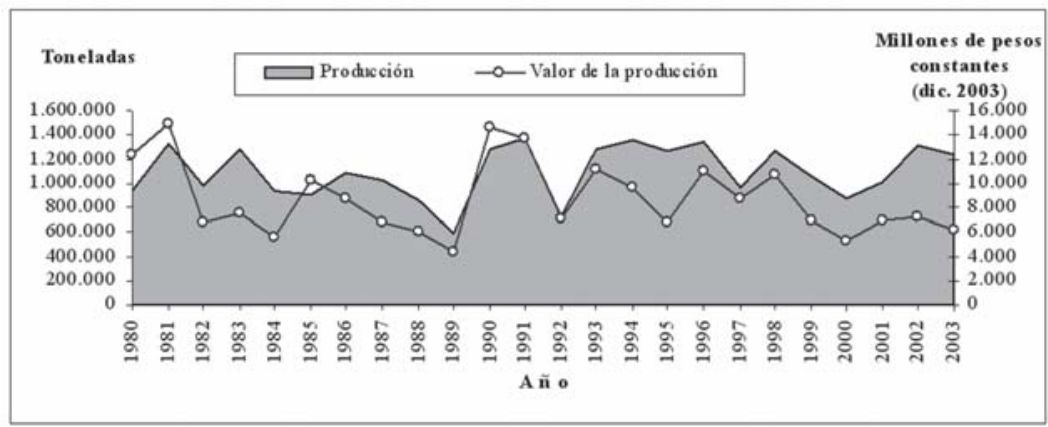

Fuente: Sistema de Información Agropecuaria de Consulta, Sagarpa, 2004, http:// www.sagarpa.gob.mx.

- Las malas prácticas agrícolas provocan degradación del suelo, lo cual incide en los precios relativos de la producción agrícola para, en una combinación de factores, convertirse en causantes de migración.

La diferencia entre ambas visiones no es trivial. Según la primera, para solucionar el problema serían necesarias políticas públicas de reconversión productiva. De acuerdo a la segunda, no bastan políticas de reconversión productiva: es necesario ubicar la competitividad relativa de Zacatecas frente al resto del país y frente a la completa apertura comercial con Estados Unidos en 2008, según lo previsto en el Tratado de Libre Comercio de América del Norte (TLCAN), y debido a la incorporación plena de China en el mercado mundial; ambos países son fuertes exportadores de frijol: Estados Unidos exporta 28\% del total mundial y China, 14\% (FAOSTAT, 1961-2004). Es indudable que una reconversión productiva mejoraría las condiciones de competitividad, pero el problema no es mejorar, sino igualar o superar las condiciones de los competidores, algo muy diferente, y para lo que se requieren políticas que abarquen no sólo la producción sino también la comercialización, la siniestralidad, ${ }^{8}$ la política fiscal y muchas otras cuestiones relacionadas.

que una porción de las 900,000 personas que anualmente migran de las regiones áridas y semiáridas de México lo hacen debido al proceso de desertificación que debilita por año 1,000 millas cuadradas de superficie de suelo y causa el abandono de otras 400 millas cuadradas de tierras de cultivo" (Schwarts y Notini, 1994: 7).

${ }^{8}$ En el caso de Zacatecas, el fenómeno meteorológico puede ser responsable de $14 \%$ de las variaciones en la producción de frijol de temporal entre 1980 y 2003 , si se consideran las diferencias entre superficie sembrada y cosechada (Sagarpa, 2004). 
Entonces, no es la degradación ambiental lo que actúa en favor de la migración, sino las relaciones de producción que colocan a la gran mayoría de los productores de frijol de temporal de Zacatecas en situación desventajosa frente a sus competidores, orillando a la migración laboral.

\section{Segunda paradoja: la migración está convirtiendo recurso} natural renovable, la fuerza de trabajo, en un recurso natural no renovable para las comunidades de origen

La distinción entre recursos naturales renovables y no renovables es crucial en el discurso del desarrollo sostenible. Los recursos no renovables son aquéllos cuya posible recuperación supera las expectativas humanas, como es el caso de los minerales. Los recursos renovables son los que la naturaleza reproduce o que el ser humano puede recuperar a voluntad, como es el caso de los productos agrícolas. La literatura especializada hace énfasis en la necesidad de utilizar los recursos renovables dentro de los ritmos de su recuperación, para no extinguirlos. Pero no suele aplicarse el concepto de recurso renovable a la propia naturaleza humana, como debería, ya que la fuerza de trabajo es uno de los principales recursos del proceso económico.

El caso de México -y el de Zacatecas- es elocuente acerca de los efectos de la migración sobre la fuerza de trabajo en los lugares de origen. El crecimiento espectacular de la migración desde principios de los años noventa se corresponde con un cambio en el patrón migratorio, que, para el estado de Zacatecas tiene como principales características: ${ }^{9}$

- Una creciente presencia de la emigración permanente. Mientras que entre 1990 y 1995 los migrantes permanentes representaban 57.5\%, entre 1995 y 2000 aumentaron a $81 \%$.

- Una prolongación del tiempo de estancia de los migrantes que regresan, que pasa de 11 a 13 meses.

- Una mayor participación femenina en la migración laboral, la cual pasó de un promedio de $8 \%$ en la década de los ochenta, a $28.9 \%$ en 2000 .

\footnotetext{
${ }^{9}$ Los datos que siguen se basan en la Encuesta Nacional de la Dinámica Demográfica, en sus versiones 1992 y 1997,y en el I Conteo de Población y Vivienda 1995 y el XII Censo General de Población y Vivienda 2000.
} 
- Aunque la presencia del varón jefe de familia sigue siendo dominante en el contexto de la migración internacional, en el último lustro se advierte un incremento en la participación de los hijos. De allí que también disminuya la edad promedio de los migrantes, pasando de 32 años en los ochenta, a 25.9 años en 2000. Amén de que se incrementa la migración de familias, en lugar de hombres jóvenes, como venía siendo la pauta.

En suma, se manifiesta el tránsito de un patrón migratorio con fuerte participación del migrante laboral de retorno, varón y jefe de familia, a otro caracterizado por la creciente presencia de la migración permanente con mayor proporción de hijos e hijas jóvenes e incluso familias enteras, y la prolongación de los tiempos de estancia de los migrantes laborales de retorno (Delgado Wise y Rodríguez, 2000; Moctezuma y García Zamora, 2000; Meza y Márquez, 2005).

El resultado es que durante la última década, y debido al cambio en el patrón migratorio, municipios de Zacatecas comienzan a registrar tasas de crecimiento poblacional negativas: 28 en 1995 , 34 de 57 en 2000 y en 2005, 42 de un total de 58 municipios presentan despoblamiento. Sólo cinco tienen tasas de crecimiento superiores a $1.5 \%$ anual entre 1990 y 2005. Cabe decir que los municipios que presentan las tasas más altas de despoblamiento se localizan en la región sur del estado, y que el sector más afectado es el de los jóvenes, que abarca la población comprendida entre 12 y 29 años, y con mayor intensidad a partir de los 20 años (Moctezuma y Pérez Veyna, 2006).

La depredación y degradación de los recursos ha sido la pauta en Zacatecas desde la época colonial. La entidad se integró al comercio mundial mediante la venta de plata y oro de sus minas, actividad aún vigente. Actualmente, lo que más exporta es la fuerza de trabajo, sobre todo a Estados Unidos, la mayoría de la cual no retorna. Esta derrama de fuerza de trabajo ya manifiesta serias dificultades allí donde se demanda empleo, sea porque no hay disponible, como ocurre para muchas actividades agrícolas, sea porque la comparación salarial con Estados Unidos es un desestímulo al trabajo en los lugares de origen. Se ha llegado al punto de inflexión donde, por el volumen de migración, la fuerza de trabajo en tanto recurso se convierte en no renovable para las comunidades de origen y, en consecuencia, las posibilidades de desarrollo económico se ven comprometidas. Esta disyuntiva sugiere políticas públicas que consideren a la población migran- 
te como ciudadanos transnacionales, con plenitud de derechos en ambos territorios, para que, siendo los actores de su destino, encuentren menos barreras legales en términos espaciales y puedan acceder productivamente a los recursos naturales. ${ }^{10}$

\section{Tercera paradoja: la migración se puede constituir en un proceso de empoderamiento para revertir la degradación ambiental}

Junto al aumento del número de migrantes y su estancia en Estados Unidos, también crece el volumen de las remesas enviadas desde ese país a México. Ese flujo de remesas se ha multiplicado 30 veces desde los ochenta hasta 2005, cuando alcanzó un máximo histórico de 20 mil millones de dólares (Banxico, 2006), lo que coloca a la exportación de fuerza de trabajo como la segunda fuente de divisas del país, con una contribución a la balanza de pagos que supera a las del turismo, las exportaciones agropecuarias y la industria maquiladora, y que queda sólo por debajo de la exportación de petróleo.

El monto total de remesas recibido por el estado de Zacatecas en 2003 ascendió a 481 millones de dólares. Tal magnitud equivale a una proporción del PIB que supera la participación de la agricultura $(8.2 \%$ frente a $7.6 \%)$ y ubica la producción de fuerza de trabajo migrante como la principal actividad productiva del estado (Delgado Wise, Márquez y Rodríguez, 2004).

Contradictoriamente con la tendencia a una migración sin retorno $-\mathrm{y}$ al consecuente posible descenso tendencial del monto de las remesas-, las organizaciones de migrantes en Estados Unidos han crecido de manera significativa. Según el Instituto de los Mexicanos en el Exterior, en mayo de 2003 existían 623 clubes de migrantes registrados en los distintos consulados mexicanos en Estados Unidos (Vega, 2004). No obstante, es menester reconocer que el número de clubes está subestimado, porque muchas de estas asociaciones mantienen una distancia respecto de las instancias oficiales y, por esa razón, su registro no forma parte de los archivos oficiales (Escala-Rabadán, 2004). Los estados de Zacatecas, Jalisco, Michoacán, Guerrero, Guanajuato y Oaxaca concentran $66.1 \%$ del total de clubes (más de 400), y la

\footnotetext{
${ }^{10}$ El despoblamiento absoluto conlleva dificultades para el desarrollo adicionales al propio abandono de las actividades económicas, ya que debido a la normatividad administrativa, las partidas presupuestales federales destinadas a la entidad y a los municipios disminuyen proporcionalmente con el tamaño y estructura de la población.
} 
distribución de éstos en Estados Unidos abarca las principales ciudades de California, Illinois y Nueva York (Imaz, 2004).

Así como faltan datos sobre el número de clubes, también hay diferencias acerca de la cantidad de miembros con que cuenta cada club. Más allá de estas dudas, la investigación in situ muestra que este tipo de organización tiene un amplio radio de influencia, basado fundamentalmente en su legitimidad social, que se extiende más allá de los confines de su membresía. Los distintos grados de desarrollo se expresan en el nivel de organización alcanzado, según sean clubes aislados o asociados (federaciones), tengan diferentes grados de institucionalización (formalización y funciones complejas) y posean permanencia, legitimidad social y desdoblamiento institucional (separación de funciones comunitarias, políticas y empresariales) (Moctezuma, 2004).

Una manifestación del vínculo de las comunidades de origen con los grupos de migrantes en Estados Unidos es el reconocimiento social de autonombrarse comunidades filiales o hijas. Cada una de éstas -cuyo referente directo es el lugar de origen del migrante- se convierte en un espacio privilegiado para la recreación de las raíces, identidad y cultura locales, así como el fortalecimiento de los lazos de solidaridad entre los migrantes y sus lugares de procedencia. Lo trascendente de este proceso es que rebasa el horizonte de las relaciones estrictamente familiares, para dar lugar a vínculos comunitarios de carácter transnacional.

Con el paso del tiempo, algunas comunidades filiales avanzaron hacia esquemas organizativos más formales -como los clubes o asociaciones de migrantes- que posibilitan el tránsito hacia el migrante colectivo: nuevo sujeto social que surge como subproducto contradictorio de la evolución histórica de la migración internacional (Moctezuma, 1999). En contraste con el migrante individual, este nuevo sujeto se caracteriza, entre otras cosas, por disponer de una organización formal relativamente permanente; por fortalecer, a partir de ella, los lazos de identidad cultural, pertenencia y solidaridad con sus comunidades de origen; por abrir espacios de interlocución ante diferentes instancias públicas y privadas de México y Estados Unidos, y por contar con un significativo potencial financiero expresado en fondos colectivos, que superan las limitaciones y rigidez propias de las remesas individuales o familiares, para la realización de obras de beneficio comunitario.

Zacatecas es la entidad del país que detenta la mayor y más avanzada organización de mexicanos en Estados Unidos, con alrededor de 40 mil socios distribuidos en poco más de 200 clubes, 
que a su vez se congregan en 10 federaciones del sur de California, Chicago, Oxnard, Denver, Dallas, Las Vegas, Atlanta, Houston, Waco, Florida y Carolina del Norte (Moctezuma, 2000).

En las reuniones de clubes zacatecanos en Illinois y el sur de California se han venido considerando problemas ambientales en las poblaciones de origen zacatecanas, como la ausencia de tratamiento de la basura, las aguas negras, la degradación que causan los talleres mecánicos, la tala de árboles y otros. La misma preocupación se manifestó en la Primera Conferencia Binacional sobre Proyectos Productivos, realizada en Zacatecas en diciembre de 2004. Éste es un primer indicio de la posibilidad de que las organizaciones de migrantes se constituyan en agentes de reversión de la degradación ambiental. Pero hay más. Ya existen inversiones productivas en las que migrantes de retorno están utilizando prácticas de agricultura sostenible aprendidas en Estados Unidos. Hay casos de sistemas de agricultura sin labranza (FAO, 2001) y de riego por goteo para conservar el agua. En Los Haro, Jerez, se está experimentando con un sistema de cultivos de cobertura que disminuye la erosión, aumenta la cantidad de materia orgánica en el suelo, mejora la retención de humedad y también proporciona un hábitat para insectos benéficos que controlan las plagas sin uso de químicos (Nichols, 2004). El Club Las Ánimas de Nochistlán, de la Federación de Clubes Zacatecanos del Sur de California, invirtió en la construcción de un proyecto para el tratamiento de aguas negras, aunque en este caso se tuvieron resultados infructuosos. El Club Campesinos El Remolino y el Club Social Chaquiloca, del municipio de Tepechitlán; el Club Boquilla de Abajo, del municipio de Cañitas de Felipe Pescador; el Club el Tuiche, del municipio de Nochistlán, y el Club Lo de Carrera, del municipio de Apulco, con el apoyo del Programa Tres por Uno han desazolvado las presas de estas comunidades (Moctezuma, 2005). Ejemplos de lucha por la justicia ambiental también han sido parte de la dinámica migraciónambiente en Zacatecas. A mediados de los noventa, una empresa papelera y propietarios forestales elaboraron un plan de explotación de maderas muertas en un área de 3,000 hectáreas de bosque, en el municipio de Monte Escobedo. Ello provocó una movilización social sin precedentes en ese municipio de alta migración. El bosque de pino-encino no era lo único en juego, pues éste creaba las condiciones para un ecosistema donde la riqueza en aves le valió el reconocimiento federal como Área de Importancia para la Conservación de las Aves en México del Programa AICA (Puig, 2002). Dos organizaciones locales, con el respaldo de 
migrantes de California, surgieron en defensa del bosque, constituyendo un ejemplo de la organización zacatecana transnacional en defensa de los recursos del estado.

\section{Conclusión}

La mayoría de los estudios que relacionan la migración con el ambiente lo hacen mecánicamente. Unos sugieren que el deterioro ambiental es causa de la migración. Otros señalan lo contrario, pero que la causa profunda es la pobreza. En el primer caso, la relación es claramente mecánica; en el segundo no se establecen cuáles son las intermediaciones entre las causas profundas y las aparentes, de manera que el razonamiento es también, aunque menos evidente, mecánico. En este artículo se demuestra que la principal causa de la migración radica en la productividad relativamente inferior del trabajo valorada monetariamente entre las zonas migrantes y el resto de las áreas que producen mercancías competitivas. De esta manera mostramos que la degradación de la naturaleza no puede expresarse directamente, necesita hacerlo por medio de los precios de los productos, o sea, de las relaciones sociales de producción. Establecemos así la mediación entre el ámbito ecológico y el socioeconómico, y lo ejemplificamos con el caso de Zacatecas, en México, una zona de alta migración a los Estados Unidos de América.

También mostramos que la migración tiene dos consecuencias inesperadas si las ubicamos dentro del discurso ambientalista hegemónico. La primera es que la fuerza de trabajo también puede convertirse en un recurso natural no renovable, y que, por lo tanto, este concepto, que es una de las claves en la discusión ambiental y es utilizado exclusivamente para los recursos naturales no humanos, debe extenderse a los grupos humanos en determinadas regiones y contextos. La segunda consecuencia es que la migración, aunque convierta a la propia fuerza de trabajo en recurso no renovable, puede, paradójicamente, impulsar, por medio de las remesas formas de recuperación ambiental.

\section{Bibliografía}

Banco Mundial (2005), Perspectivas Económicas Mundiales 2006, Banco Mundial, Washington.

Banxico (2006), Informe anual 2005, http:/www.banxico.org.mx/ gPublicaciones/FSPublicaciones.html, 3 de junio de 2006. 
Black, Richard (2001), Environmental Refugees: Myth or Reality?, Working Paper 34, CDE, University of Sussex, http://www. unhcr.ch/refworld/pubs/pubon.htm, 1 de agosto de 2005 .

Conapo (Consejo Nacional de Población) (2002), Índice de intensidad migratoria México-Estados Unidos, 2000, Conapo, México.

Conapo (Consejo Nacional de Población) (2004), Pérdida anual neta por migración en Estados Unidos por periodo, 19602003, http://www.conapo.gob.mx/mig_int/series/g06.ppt., 3 de marzo de 2005.

Conapo (Consejo Nacional de Población) (2006), El Conapo, el INEGI y el Colmex concilian cifras de la dinámica demográfica del país para el periodo 2000-2005, Comunicado de prensa 37/06, http://www.conapo.gob.mx/prensa/2006/ 372006 bol.pdf, 19 de septiembre de 2006.

Delgado Wise, Raúl y Humberto Márquez (2006), “The Mexico-United States Migratory System: Dilemas of Regional Integration, Development, and Emigration", ponencia presentada en la Conferencia Migration and Development: Perspectives from the South, Bellagio, 10 al 13 de julio.

Delgado Wise, Raúl y Héctor Rodríguez (2000), “Las nuevas tendencias de la migración internacional: el caso de Zacatecas", Comercio Exterior, revista del Banco de Comercio Exterior, 50 (5): 371-380.

Delgado Wise, Raúl, Humberto Márquez y Héctor Rodríguez (2004), "Organizaciones transnacionales de migrantes y desarrollo regional en Zacatecas", Migraciones Internacionales, revista de El Colegio de la Frontera Norte, 2 (4): 159-181.

El-Hinnawi, Essam (1985), Environmental Refugees, United Nations Environment Programme, Nairobi.

Encuesta Nacional de Fecundidad y Salud (ENFES) de 1987, ejecutada por la Secretaría de Salud. 
Encuesta Nacional de la Dinámica Demográfica (ENADID), realizada por primera vez en 1992 por el Instituto Nacional de Estadística, Geografía e Informática (INEGI).

Escala-Rabadán, Luis (2004), “Migraciones y formas organizativas en los Estados Unidos: los clubes y federaciones de migrantes mexicanos en California", en Guillaume Lanly y Basilia Valenzuela (comps.), Clubes de migrantes oriundos mexicanos en los Estados Unidos. La política transnacional de la nueva sociedad migrante, Universidad de Guadalajara, México, pp. 425-449.

FAO (Organización para la Alimentación y la Agricultura) (2001), "Labranza cero: cuando menos es más”, Enfoques, http:// www.fao.org/ag/esp/revista/0101sp1.htm, 25 de abril de 2005.

FAOSTAT (1961-2004), http://www.fao.org, 3 de marzo de 2005.

Foladori, Guillermo (2005), "El papel de la ciencia en la moderna conciencia ambiental. El caso de los desastres naturales", Saúde e Ambiente, 6 (1), Univille, Joinville, http:// www.univille.net/pagina.phtml?id_pagina $=3930$.

Homer-Dixon, Thomas (1994), "Environmental Scarcities and Violent Conflict: Evidence from Cases", International Security, 19 (1): 5-40, http://www.library.utoronto.ca/pcs/ evidence/evid1.htm, 1 de agosto de 2005.

Hugo, Graeme (1996), "Environmental Concerns and International Migration”, International Migration Review, 30 (1): 105-131.

Imaz, Cecilia (2004), "Poder político de las organizaciones transnacionales de migrantes mexicanos en sus comunidades de origen. Estudio comparativo de clubes sociales de migrantes en Nayarit-California y Puebla-Nueva York", en Guillaume Lanly y Basilia Valenzuela (comps.), Clubes de migrantes oriundos mexicanos en los Estados Unidos. La politica transnacional de la nueva sociedad migrante, Universidad de Guadalajara, México, pp. 375-382. 
Jacobson, Jodi (1988), Environmental Refugees: a Yardstick of Habitability, World Watch Paper, 86, World Watch Institute, Washington.

Meza, Claudia y Humberto Márquez (2005), "Cambios en el patrón migratorio y pobreza en Zacatecas”, en Raúl Delgado y Beatrice Knerr (coords.), Contribuciones al análisis de la migración internacional y el desarrollo regional en México, Miguel Ángel Porrúa-Universidad Autónoma de Zacatecas, México, pp. 241-273.

Moctezuma, Miguel (1999), Redes sociales, comunidades filiales, familias y clubes de migrantes. El circuito migrante Sain Alto, Zac.-Oakland, Cal., tesis doctoral, El Colegio de la Frontera Norte, Tijuana.

Moctezuma, Miguel (2000), "La organización de los migrantes zacatecanos en Estados Unidos", Cuadernos Agrarios, 19/ 20: 81-104.

Moctezuma, Miguel (2004), Morfología y desarrollo de las asociaciones de mexicanos en EU. El migrante colectivo como sujeto social, http://www.migracionydesarrollo.org, $11 \mathrm{de}$ agosto de 2005 .

Moctezuma, Miguel (2005), "Hacia una tipología de los migrantes internacionales con base en su capacidad de inversión", en Raúl Delgado y Beatrice Knerr (coords.), Contribuciones al análisis de la migración internacional y el desarrollo regional en México, Miguel Ángel Porrúa-Universidad Autónoma de Zacatecas, México, pp-119-133.

Moctezuma, Miguel y Rodolfo García Zamora (2000), "La transición hacia un nuevo patrón migratorio internacional zacatecano", en Miguel Moctezuma (comp.), Memorias del Foro Sivilla-Fundación Produce sobre temas de migración, Conacyt, Zacatecas, pp. 31-39.

Moctezuma, Miguel y Óscar Pérez Veyna (2006), La juventud de Zacatecas en un contexto de alta migración y bajas oportunidades, Instituto Nacional de la Juventud, México. 
Myers, Norman (2005), "Environmental Refugees: An Emergent Security Issue", $13^{\text {th }}$ Economic Forum. Session III - Environment and Migration, EF.NGO/4/05, Praga, 23-27 de Mayo, http://64.233.161.104/search?q=cache:-gQ7N H938BMJ:www.osce.org/item/14488.html+Myers + $200+$ million + sea + level\&hl=es\&client $=$ firefox $-\mathrm{a}, 1 \mathrm{de}$ agosto de 2005 .

Nichols, Sandra (2004), “Transferencia de tecnolgía agrícola por medio de la migración mexicana", Desarrollo de Base, 25 (1): 27-34.

OIT (Organización Internacional del Trabajo) (2006), Migración laboral en el siglo XXI: ¿De muchos, uno?, http://www.ilo. org/public/spanish/bureau/inf/features/06/migration.htm, 20 de julio de 2006.

ONU (Organizaciones de las Naciones Unidas) (1991), "Relationships Between Population and the Environment in Rural Areas of Developing Countries", Population Bulletin of the United Nations, 31-32.

Puig, Francisco (2002), El bosque tropical caducifolio de Monte Escobedo: nuevo argumento para la propuesta de Área Natural Protegida, tesis de licenciatura en ciencias ambientales, Universidad Autónoma de Barcelona-ITESM campus Zacatecas-Universidad Autónoma de Zacatecas, Zacatecas.

Richmond, Anthony H. (1995), "The Environment and the Refugees: Theoretical and Policy Issues", Population Bulletin of the United Nations, 39: 1-17.

Sagarpa (Secretaría de Agricultura, Ganadería, Desarrollo Rural, Pesca y Alimentación) (2004), Información Estadistica. Sistema de Información agropecuaria y de consulta, http://www.sagarpa.gob.mx, 3 de marzo de 2005.

Sagarpa-Sedagro (Secretaría de Agricultura, Ganadería, Desarrollo Rural, Pesca y Alimentación-Secretaría de Desarrollo Agropecuario) (1987-2003), Información estadística, http:/ /oiedrus.zacatecas.gob.mx, 3 de marzo de 2005. 
Schwartz, Michelle Leighton y Jessica Notini (1994), Desertification and Migration: Mexico and the United States, Research Paper 1, U.S. Commission on Inmigraton ReformNatural Heritage Institute, San Francisco, http://scholar. google.com/url?sa $=U \& q=h t t p: / / w w w . u t e x a s . e d u / l b j / u s-$ cir/respapers/, 13 de abril de 2005.

Schwartz, Michelle Leighton y Jessica Notini (1995), "Preliminary Report on Desertification and Migration: Case Studies and Evaluation", en J. Puigdefábregas y T. Mendizábal (eds.), Desertification and Migrations, International Symposium on Desertification and Migrations, Geoforma Ediciones, Logroño.

Suhrke, Astri (1994), "Environmental Degradation and Population Flows", Journal of International Affairs, 47 (2): 473-496.

Swain, Ashok (1996), "Environmental Migration and Conflict Dynamics: Focus on Developing Regions", Third World Quarterly, 17 (5): 959-974.

Valadez, Alfredo (2005), "Erosionadas 300 mil hectáreas de tierras de cultivo en Zacatecas", entrevista a Agustín Rumayor y Jorge Zegbe, La Jornada, 8 de agosto.

Vega Briones, Gustavo (2004), "La formación de clubes del Estado de México. Mecanismos de organización de nuevas comunidades de migrantes mexicanos en los Estados Unidos”, en Guillaume Lanly y Basilia Valenzuela (comps.), Clubes de migrantes oriundos mexicanos en los Estados Unidos. La política transnacional de la nueva sociedad migrante, Universidad de Guadalajara, México, pp. 315-346.

Recibido: 5 de enero de 2006. Reenviado: 11 de mayo de 2006. Aprobado: 17 de octubre de 2006.

Rodolfo García-Zamora. Doctor en ciencias económicas por la Universidad Autónoma de Barcelona. Actualmente es profesorinvestigador del doctorado en estudios del desarrollo de la Universidad Autónoma de Zacatecas. Sus líneas de investigación se centran en migración, remesas y desarrollo regional. Su publica- 
ción más reciente es Migración, remesas y desarrollo, Universidad Autónoma de Zacatecas, México, 2005.

Óscar Pérez Veyna. Doctor en administración por la Universidad Autónoma de Aguascalientes. Actualmente es profesor-investigador del doctorado en estudios del desarrollo de la Universidad Autónoma de Zacatecas. Su línea de investigación se centra en la Estadística Experimental.

Guillermo Foladori. Doctor en economía por la Universidad Nacional Autónoma de México. Actualmente es profesor-investigador en el doctorado en estudios del desarrollo por la Universidad Autónoma de Zacatecas. Sus líneas de investigación se centran en medio ambiente y desarrollo, nanotecnología. Entre sus publicaciones destacan: Por una sustentabilidad alternativa, Unión Internacional de los Trabajadores de la Alimentación y afines, en coautoría con Naína Pierri, 2005, Montevideo, 110 pp.; ¿Sustentabilidad? Desacuerdos sobre el desarrollo sustentable, Miguel Ángel Porrúa, México, 2005, 250 pp.

Raúl Delgado Wise. Doctor en ciencias sociales por la Universidad de Pennsylvania. Actualmente es profesor-investigador del doctorado en estudios del desarrollo de la Universidad Autónoma de Zacatecas. Sus líneas de investigación se centran en migración internacional y desarrollo. Entre sus publicaciones destacan: Contribuciones al análisis de la migración internacional y el desarrollo regional en México (en coautoría con Beatrice Knerr), Miguel Ángel Porrúa, México, 2005.

Miguel Moctezuma. Doctor en ciencias sociales por El Colegio de la Frontera Norte. Actualmente es profesor-investigador del doctorado en estudios del desarrollo de la Universidad Autónoma de Zacatecas. Sus líneas de investigación se centran en migración internacional y organizaciones de migrantes. Su publicación más reciente es La cultura y el simbolismo de la migración y las remesas. Reflexiones a partir de la experiencia de Zacatecas, en Raúl Delgado y Beatrice Knerr (comps.), Contribuciones al análisis de la migración internacional y el desarrollo regional en México, Miguel Ángel Porrúa, México, 2005.

Elivier Reyes. Maestro en administración por la Universidad Autónoma de Zacatecas y doctorante en estudios del desarrollo en 
la Universidad Autónoma de Zacatecas. Su línea de investigación se centra en el desarrollo agropecuario.

Humberto Márquez. Maestro en ciencias por la Universidad Autónoma de Zacatecas y doctorante en estudios del desarrollo en la Universidad Autónoma de Zacatecas. Su línea de investigación se centra en migración internacional y desarrollo. Su publicación más reciente es "El desarrollo participativo transnacional basado en las organizaciones de migrantes”, Problemas del Desarrollo, 37 (144).

Patricia Rivera. Maestra en ciencias por el Colegio de la Frontera Norte y doctorante en estudios del desarrollo en la Universidad Autónoma de Zacatecas. Su línea de investigación se centra en medio ambiente y desarrollo. 